\title{
Quantitation of Angiogenesis and Antiangiogenesis In Vivo, Ex Vivo and In Vitro - an Overview
}

\author{
Mahtab Bahramsoltani, Johanna Plendl, Pawel Janczyk, Pia Custodis and Sabine Kaessmeyer \\ Institute of Veterinary Anatomy, Faculty of Veterinary Medicine, Freie Universität Berlin, Germany
}

\begin{abstract}
Summary
Angiogenesis is defined as the sprouting of new capillaries from pre-existing ones. Angiogenesis is a prerequisite for growth and differentiation of organs and tissues and is involved in many pathological processes, for example growth and metastasis of tumours.

Numerous in vivo and in vitro models of angiogenesis have been developed in order to identify and analyse pro- and antiangiogenic factors. This review aims at outlining the topic of quantitation of angiogenesis and antiangiogenesis in these models.
\end{abstract}

Keywords: angiogenesis, antiangiogenesis, quantitation, in vivo, ex vivo and in vitro models

\section{Requirements for quantitation of angiogenesis and antiangiogenesis}

Clinical application of pro- and antiangiogenic factors is still restricted. Apart from their specific action, it is still unknown, at which stage of the angiogenic cascade these agents affect angiogenesis. The influence of a factor that stimulates or inhibits angiogenesis may occur at several levels of the angiogenic cascade, e.g. degradation of the basal membrane, endothelial cell migration/proliferation and three-dimensional organisation of endothelial cells (Auerbach et al., 2003). Besides, knowledge of the substance concentration necessary for manipulation of angiogenesis is essential for the clinical use of pro- or antiangiogenic factors (Jain et al., 1997).

Numerous in vivo and in vitro investigations deal with the identification and characterisation of the effect of substances that stimulate or inhibit angiogenesis (Auerbach and Auerbach, 1994). However, reliable statements about the effect of angiogenic stimulators or inhibitors can only be made by quantitation of angiogenesis, i.e. presentation of angiogenesis in measurable parameters (terms) (Auerbach et al., 1991). In almost all in vivo models quantitation of angiogenesis is based on calculation of vessel number, which represents the end-point and not the process of angiogenesis. Quantitation of angiogenesis in in vitro models is accomplished either on the basis of quantitation of cell migration or proliferation or, rarely, on three-dimensional organisation of endothelial cells. Nevertheless, to provide a significant statement about the effect of a pro- or antiangiogenic factor, the method of quantitation of angiogenesis should include all phases of the angiogenic cascade (Auerbach et al., 2003).
Criteria to be met for a significant quantitation of the effect of soluble proangiogenic and antiangiogenic factors have only been established by Jain et al. (1997), however, without distinguishing between in vivo and in vitro models of angiogenesis.

Quantitation of newly formed vessels/vessel-like structures is a prerequisite for in vivo and in vitro investigations. Data on length and area covered by the vessel-like structures, as well as number of new vessels/vessel-like structures and extension of the basal membrane should be collected. In in vivo investigations it is necessary to differentiate newly formed vessels from those already existing at the beginning of the trial.

For clinical use of angiogenic stimulators or inhibitors, doseeffect relationship should be established. Thus, the precise concentration of the factor necessary for starting pro- or antiangiogenic effects has to be determined by in vivo investigation.

Finally, for the routine practice of a method, quantitation of angiogenesis should be conducted quickly and simply, reproducibly and cost efficiently (Jain et al., 1997).

\section{Models for quantitation of angiogenesis and antiangiogenesis in vivo}

Angiogenesis is a complex process in which the interaction of endothelial cells with surrounding tissue (e.g. via adhesion molecules and cytokines) plays a decisive role. In order to develop therapeutic strategies, the effects of soluble pro- or antiangiogenic factors have been commonly investigated in in vivo models. 
Tab. 1: Advantages and disadvantages of models for quantitation of angiogenesis and antiangiogenesis in vivo

\begin{tabular}{|c|c|c|c|}
\hline Model & Advantages & Disadvantages & References \\
\hline Cornea model & $\begin{array}{l}\text { - no interfering background due } \\
\text { to the absence of pre-existing } \\
\text { vessels } \\
\text { - permanent monitoring of } \\
\text { vessel growth possible }\end{array}$ & $\begin{array}{l}\text { - very painful to animals (high } \\
\text { sensibility of cornea) } \\
\text { - very complex surgical procedures } \\
\text { - possible false results due to } \\
\text { unavoidable inflammation-based } \\
\text { angiogenesis } \\
\text { - unsuitable for quantitation of tumour } \\
\text { angiogenesis or antiangiogenesis } \\
\text { - special skills required }\end{array}$ & $\begin{array}{l}\text { Jain et al., } 1997 \\
\text { Blackwell et al., } 2000 \\
\text { Shan et al., } 2001 \\
\text { Auerbach et al., } 2003\end{array}$ \\
\hline $\begin{array}{l}\text { Chorioallantoic membrane } \\
\text { (CAM) model }\end{array}$ & $\begin{array}{l}\text { - inexpensive } \\
\text { - easy to perform } \\
\text { - high-throughput of specimens } \\
\text { - permanent monitoring of vessel }\end{array}$ & $\begin{array}{l}\text { - interfering background of } \\
\text { physiological angiogenesis } \\
\text { - reduced reproducibility } \\
\text { - possible false results due to } \\
\text { unavoidable inflammation-based } \\
\text { angiogenesis } \\
\text { - only short time-frame for } \\
\text { investigation (one week) } \\
\text { - limited comparability with mammals } \\
\text { - special skills required }\end{array}$ & $\begin{array}{l}\text { Spanel-Borowski et al., } 1988 \\
\text { Knighton et al., } 1991 \\
\text { Bell and Brickell, } 1997 \\
\text { Ribatti et al., } 2001\end{array}$ \\
\hline $\begin{array}{l}\text { Dorsal skin fold } \\
\text { chamber model }\end{array}$ & $\begin{array}{l}\text { - long-term studies possible } \\
\text { (up to } 3 \text { weeks) } \\
\text { - permanent monitoring of vessel } \\
\text { growth possible }\end{array}$ & $\begin{array}{l}\text { - very painful and stressful to } \\
\text { animals for a long time } \\
\text { - background of vessels } \\
\text { - demanding surgical procedures } \\
\text { - special skills required }\end{array}$ & $\begin{array}{l}\text { Vollmar et al., } 2001 \\
\text { Menger et al., } 2002 \\
\text { Staton et al., } 2004\end{array}$ \\
\hline $\begin{array}{l}\text { Subcutaneous air sack } \\
\text { model }\end{array}$ & $\begin{array}{l}\text { - inexpensive } \\
\text { - simple procedure } \\
\text { - no immune cross-reaction } \\
\text { - tumour cells of foreign origin } \\
\text { can be used }\end{array}$ & $\begin{array}{l}\text { - very painful and stressful to } \\
\text { animals over a long time } \\
\text { - high number of animals needed } \\
\text { - background of vessels } \\
\text { - no permanent monitoring of } \\
\text { vessel growth possible } \\
\text { - time-consuming preparation } \\
\text { - subjective classification of parameters } \\
\text { - special skills required }\end{array}$ & $\begin{array}{l}\text { Lichtenberg et al., } 1997 \\
\text { Oikawa et al., } 1997\end{array}$ \\
\hline $\begin{array}{l}\text { Models with skin } \\
\text { preparations }\end{array}$ & - very simple procedure & $\begin{array}{l}\text { - high number of animals needed } \\
\text { - no permanent monitoring of vessel } \\
\text { growth possible } \\
\text { - immune cross-reaction } \\
\text { - low reproducibility } \\
\text { - special skills required }\end{array}$ & $\begin{array}{l}\text { Jain et al., } 1997 \\
\text { Bruns et al., } 2000\end{array}$ \\
\hline Imaging models & $\begin{array}{l}\text { - permanent monitoring of vessel } \\
\text { growth possible } \\
\text { - minor invasive procedure } \\
\text { - low number of animals needed }\end{array}$ & $\begin{array}{l}\text { - stressful to animals due to long du- } \\
\text { ration of handling and immobilisation } \\
\text { - expensive and sophisticated } \\
\text { equipment needed } \\
\text { - special skills required }\end{array}$ & $\begin{array}{l}\text { Denis et al., } 2002 \\
\text { Dong et al., } 2007\end{array}$ \\
\hline Whole animal models & $\begin{array}{l}\text { - high-throughput } \\
\text { - rapid and inexpensive } \\
\text { (dye injection) } \\
\text { - permanent monitoring of vessel } \\
\text { growth possible } \\
\text { (GFP transgenic lines) }\end{array}$ & $\begin{array}{l}\text { - high number of animals needed } \\
\text { - limited comparability to mammals } \\
\text { - fixation required } \\
\text { - high costs of transgenic lines } \\
\text { - special skills required }\end{array}$ & $\begin{array}{l}\text { Schwerte and Pelster, } 2000 \\
\text { Lawson and Weinstein, } 2002 \\
\text { Cross et al., } 2003\end{array}$ \\
\hline
\end{tabular}


In the following, different animal models for investigation and quantitation of angiogenesis are described and finally critically presented regarding their advantages and disadvantages (Tab. 1).

\subsection{Cornea model}

In the cornea of rabbits, rats and mice growth of vessels sprouting into the cornea, as the result of angiogenic stimulation, can be investigated and quantified (Fig. 1). Due to the physiologically non-vascularised cornea of the adult individual, this model is one of the most applied animal models for investigation of angiogenesis and antiangiogenesis (Henkind, 1978).

Angiogenesis is stimulated by inserting implants into the extensively sensitively innervated cornea (Gimbrone et al., 1974; Langer and Folkman, 1976; Gaudric et al., 1992, Wang and Shi, 2009). Evaluation and quantitation of angiogenesis is carried out by the measurement of vessels sprouting into the cornea in defined areas. These investigations are made by image analysis, either in vivo using an operation microscope and taking photographs (Ziche et al., 1994; Joussen et al., 1999; Gonzalez et al., 2001; Cao et al., 2002) or, after killing of the animals, in histological sections of the cornea (Tong et al., 2006).

\subsection{Chorioallantoic membrane (CAM) model}

Quantitation of angiogenesis may also be performed by observing the growth of chorioallantoic vessels through a fenestration in the eggshell (Ausprunk et al., 1975). Auerbach et al. (1974) introduced a modification by transferring the chick embryos with their foetal membranes to Petri dishes after 3 days of incubation. As soon as the chick embryo and extraembryonic membranes are in the Petri dish, the CAM appears on the surface and spreads as an even membrane over the whole dish.

To investigate soluble factors with an angiogenic effect, the CAM is mostly used between the $7^{\text {th }}$ and $12^{\text {th }}$ day of incubation (Ribatti et al., 1996; 2001; Nguyen et al., 1994; Sheu et al., 1998; Brooks et al., 1999; Yokoyama et al., 2000; Célérier et al; 2002; Doukas et al., 2006, Jung et al., 2009). Physiologically,

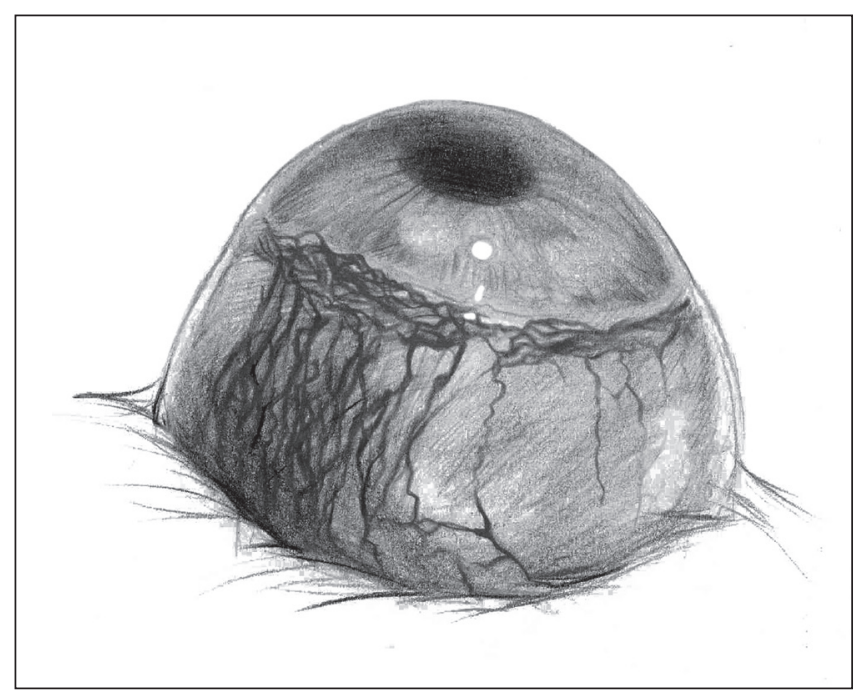

Fig. 1: Quantitation of angiogenesis in vivo: Cornea model the highest parameters of angiogenesis in the CAM are found between the $4^{\text {th }}$ and $11^{\text {th }}$ day of incubation. Thus, this model can be used within this timeframe to study angiogenic inhibitors without previous stimulation of angiogenesis.

For investigation of pro- or antiangiogenic effects, the test factors are implanted into specific carrier substances, like gelatine sponges or microbiological test plates, and placed onto the chorioallantoic membrane. Angiogenesis can be documented continuously by taking images of the CAM in ovo or in the dishes, or as a one-point investigation by fixation of the foetal membranes and histological examination (Ribatti et al., 1997; 2002; Sheu et al., 1998; Brooks et al., 1999). Quantitation of angiogenesis and antiangiogenesis is carried out by calculating the total vessel length, the vessel branching points and/or the vessel density over defined image areas.

\subsection{Dorsal skinfold chamber model}

Implantation of a transparent observation chamber into the rabbit ear was already realised by Sandison in 1924. This chamber technique was adapted to the mouse by Algire (1943). The disadvantage of these early chamber models was that the investigated tissue consisted mainly of newly formed granulation tissue. Therefore, modern chamber models aim to provide permanent tissue preparations that are neither irritated by the chamber itself (by using materials like titanium or DuraconTM) nor by the implantation procedure (Menger et al., 2002; Ushiyama et al., 2004).

In recent years, the dorsal skin fold chamber of mice (Fig. 2), rats and hamsters, a permanent window preparation for quantitation of angiogenesis, has been used most commonly (Papenfuss et al., 1979; Endrich et al., 1980; Lehr et al.; 1993; Torres Filhe et al., 1995; Abshagen et al., 2008). The tissues used for microscopic investigations consist of dermis, subcutis and skeletal muscles (Musculus cutaneus trunci).

Most frequently, angiogenesis is induced by implantation of tumour spheroids but also, for example, follicles with oocytes (Torres Filho et al., 1995; Vajkoczy et al., 2000; Vollmar et al.,

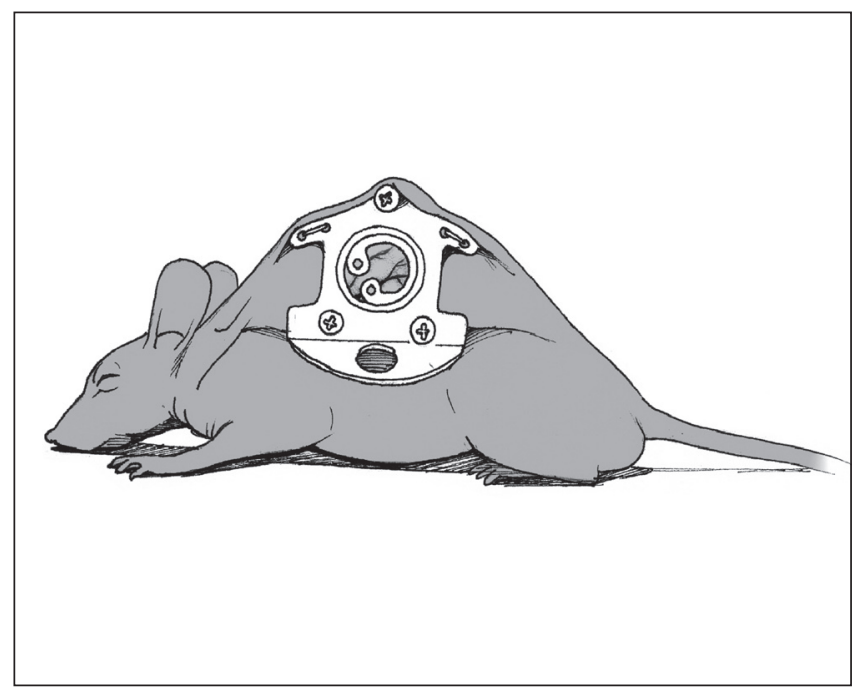

Fig. 2: Quantitation of angiogenesis in vivo: Dorsal skinfold chamber model 
2001). Vessel growth within the inspection window is observed microscopically. For this vessels are visualised by intravenous administration of fluorescein-isothiocyanate-dextran (FITCdextran) or other dyes, and the non-anaesthetised animals are immobilised in a plexiglass tube attached to the microscope. Thus, quantitation of angiogenesis or antiangiogenesis can be carried out by image analysis of photographs taken with a camera installed at the microscope. Collected data comprise the vessel density, total vessel length or vessel volume. The specific criterion for new vessel formation is their disordered growth in opposite to typical parallel capillary organisation of skeletal muscles.

\subsection{Subcutaneous air sack model}

The subcutaneous air sack model for investigation and assessment of angiogenesis and antiangiogenesis was developed in the rat by Lichtenberg et al. in 1997 and was adapted to the mouse by Basaki et al. (2001).

The air sack is induced by injection of air subcutaneously into the back skin fold. For investigation of antiangiogenic substances, angiogenesis is first stimulated by surgical implantation of cellulose sponges, causing vasoproliferation, or by a tumour cell coated membrane (Lichtenberg et al., 1999; Basaki et al., 2001; Semba et al. 2004; Yamamoto et al., 2009). The evaluation and quantitation of angiogenesis is performed by measurement of radiation of intravenously injected isotope-labelled antibodies. After killing of animals, skin is removed from the membrane covering the air sack and semi-quantitative evaluation of angiogenesis is performed by estimating the expansion of vessel proliferation in situ. Estimation is accomplished by subjective classification of parameters and scores.

\subsection{Models with skin preparations}

Investigation and quantitation of angiogenesis has been performed by many investigators in skin preparations of rats and mice (e.g. Plunkett and Hailey, 1990; Runkel et al., 1991; Hoffmann et al., 1997; Lenander and Holmgren, 1999; Wild et al., 2000; Guo et al., 2001; Liapakis et al., 2008). For this purpose tumour cell suspensions are injected subcutaneously and an- giogenesis is observed by counting new sprouting capillaries, either as a one-point measurement after killing the animals (Lenander and Holmgren, 1999; Wild et al., 2000; Guo et al, 2001) or over time by opening the skin flap surgically every second day (Runkel et al., 1991). In other studies the quantitation of angiogenesis is carried out by measuring the haemoglobin concentration in the examined skin area (Plunkett and Hailey, 1990; Hoffmann et al., 1997).

\subsection{Imaging models}

In contrast to most in vivo models of angiogenesis, where tissue specimens must be examined histologically to accomplish analysis and quantitation of vessels, models using imaging systems like ultrasonography allow the continuous evaluation of angiogenesis in the same animal over time (Dong et al., 2007).

Denis et al. (2002) developed an in vivo method for longterm investigation of angiogenesis in rats, displaying vessels with the aid of Power Doppler sonography. In this model, animals receive a subcutaneous injection of N-methyl-N-nitrosourea in the area of the mammary complexes. The size of the developing tumours is then measured over time. Sonographic tumour investigation is carried out at different time points. Tumour examination is accomplished by applying a linear transducer, and pictures subjectively estimated to have the highest Doppler signal are digitally photographed and analysed by determination of intensity of the Doppler signal for each pixel in accordance with the colour scale of the Power Doppler signal. The investigators designated "regions of interest (ROI)" in such digital pictures, which correspond to the measured size of the tumour. In these ROI, vascularisation and angiogenesis are quantified by means of different scoring approaches.

Several years ago the application of ultrasonography for quantitation of angiogenesis was modified by injection of contrast agent microbubbles for a better vessel visualisation (McDonald and Choyke, 2003; Lucidarme et al., 2006). Quantitation of angiogenesis is carried out with a morphometric analysis program by measuring the amount of microbubbles in defined ROI.

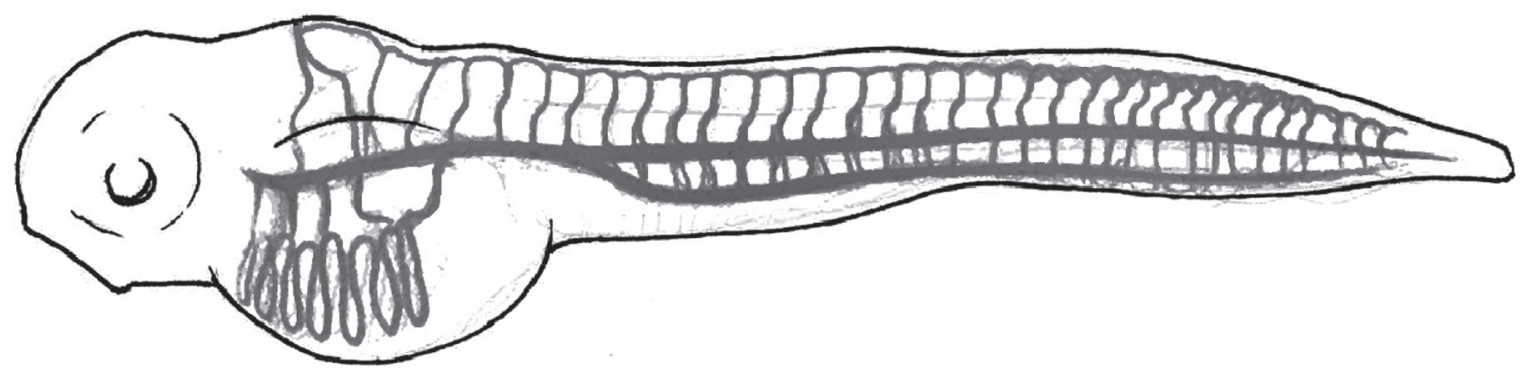

Fig. 3: Quantitation of angiogenesis in vivo: Zebrafish model 
As the latest innovation in this field, microbubbles are labelled with antibodies targeting endothelial cell receptors (Lindner, 2004; Willmann et al., 2008; Kiessling et al., 2009). Willmann et al. (2008) further refined this method by using microbubbles labelled with antibodies against vascular endothelial growth factor receptor 2 (VEGFR2), which is highly expressed in tumour vessels. In this way these authors compared the use of non-targeted and VEGFR2-targeted microbubbles and discovered a significantly higher average video intensity when using the labelled microbubbles ( $\mathrm{p}<0.001)$.

\subsection{Whole animal models}

Small vertebrate organisms, like zebrafish embryos and Xenopus tadpoles, which are used primarily in drug discovery and developmental biology studies, are often used in studies on angiogenesis (Rubinstein, 2003). While Xenopus tadpoles are particularly adapted for investigations on lymphangiogenesis, zebrafish embryos are considered to be an ideal vertebrate model to study angiogenesis (Ny et al., 2006; Kazanskaya et al, 2008). They exhibit the advantage of easy visualisation of vessels and vessel development because of their external development and optical transparency during the first days of development (Fig. 3). Additionally, these conditions provide the opportunity to use fluorescent markers to label specific structures and cells like endothelial cells (Lawson and Weinstein, 2002). The vessel architecture of zebrafish embryos, which is completely developed 3 days after fertilisation, is very simple and known in detail. It consists of a dorsal aorta and a posterior cardinal vein on each side. A network of secondary branches emanates from these vessels, including dorsoventrally aligned intersegmental vessels, two separate dorsal longitudinal anastomotic vessels joining the intersegmental vessels and longitudinal parachordal vessels (Eriksson and Löfberg, 2000). Owing to the lucidity of the vessels in this animal, angiogenesis can be investigated and quantified very easily (Zhong et al., 2001).

Most commonly, visualisation of blood vessels is carried out via whole mount in situ hybridization (Lee et al., 2002; Ober et al., 2004; Ma et al., 2007), detection of endogenous alkaline phosphatase activity (Serbedzija et al., 1999) or microangiography (Feldner et al., 2005).

The whole mount in situ hybridisation technique is used to detect factors expressed in endothelial cells. Ober et al. (2004) for example used this method to label transcripts of VEGFC to verify its requirement for vascular development, and Ma et al. (2007) revealed the role of survivin in angiogenesis during zebrafish embryonic development. Zebrafish are fixed in paraformaldehyde, cut into sections and processed for in situ hybridisation. Investigation and quantitation of angiogenesis is carried out by image processing.

Due to the fact that all these methods are very time consuming and that chemical fixation of the animals is necessary for in situ hybridisation and the detection of alkaline phosphatase activity, Cross et al. (2003) developed a transgenic zebrafish line with fluorescent blood vessels by driving expression of a green reef coral fluorescent protein (G-RCFP) with a promoter for VEGFR2. They demonstrated the utility of these animals for investigation and quantitation of angiogenesis by applying the antiangiogenic compounds SU5416 and SU6668. Effects on angiogenesis were determined by presence or absence of sprouts from the dorsal aorta. They concluded from their results that in future quantitation of angiogenesis in this model would be accomplished simply by fluorescent detection in a microplate reader.

\section{Models for quantitation of angiogenesis and antiangiogenesis ex vivo}

Ex vivo models are based upon cultivation of aorta explants from embryonic or adult rats and mice (Blacher et al., 2001; Akimoto et al., 2002) or from placental vessels of different species (Brown et al., 1996; Jung et al., 2001) in three-dimensional matrices such as collagen I, fibrin and Matrigel ${ }^{\circledR}$, an extract from a basal membrane derived tumour (Nicosia and Ottinetti,1990a; 1990b; Blacher et al., 2001; Kruger and Figg, 2001).

The explants are examined by phase contrast microscopy until the development of micro-vessels becomes visible. To quantify

Tab. 2: Advantages and disadvantages of models for quantitation of angiogenesis and antiangiogenesis ex vivo

\begin{tabular}{|l|l|l|l|}
\hline Model & Advantages & Disadvantages & References \\
\hline $\begin{array}{l}\text { Rat/mouse/chick } \\
\text { aortic ring model }\end{array}$ & $\begin{array}{l}\text { - similar to in vivo angiogenesis } \\
\text { - influence of non-endothelial } \\
\text { cells can be investigated } \\
\text { - no interfering inflammatory } \\
\text { reaction } \\
\text { - inexpensive }\end{array}$ & $\begin{array}{l}\text { - very restricted reproducibility } \\
\text { - time-consuming } \\
\text { - unsuitable for quantitation of } \\
\text { tumour angiogenesis or } \\
\text { antiangiogenesis }\end{array}$ & $\begin{array}{l}\text { Auerbach et al., 2000 } \\
\text { Kruger et al., 2001 } \\
\text { Auerbach et al., 2003 }\end{array}$ \\
\hline $\begin{array}{l}\text { Human placental } \\
\text { vessels model }\end{array}$ & $\begin{array}{l}\text { - human tissue readily available } \\
\text { - similar to in vivo angiogenesis } \\
\text { - influence of non-endothelial } \\
\text { cells can be investigated } \\
\text { - no interfering inflammatory } \\
\text { reaction } \\
\text { - inexpensive }\end{array}$ & $\begin{array}{l}\text { - very restricted reproducibility } \\
\text { - unsuitable for quantitation } \\
\text { of tumour angiogenesis } \\
\text { or antiangiogenesis }\end{array}$ & \\
\hline
\end{tabular}


angiogenesis, gel blocks are cut parallel to the lateral aortic border and the total length of microvascular contour is calculated.

Blacher et al. (2001) estimated vessel quantity, maximum vessel length and number of vessel branches with the rat aortic ring assay using a binary method of image analysis. With the same model Kruger and Figg (2001) quantified the area covered by vessels as the total amount of white pixels, declared as vessel density. Advantages and disadvantages of these models are shown in Table 2.

\section{Models for quantitation of angiogenesis and antiangiogenesis in vitro}

In vitro investigations concerning angiogenesis have been performed in cultured macrovascular and microvascular endothelial cells (e.g. Montesano et al., 1986; Hoying and Williams, 1996; Iwahana et al., 1996; Lang et al., 2000) or in co-cultures of different cells (e.g. Babaei and Stewart, 2002; Ramsauer et al., 2002; Velazquez et al., 2002). In vitro models provide significant insights, particularly into cellular and molecular angiogenic control mechanisms and different levels of the angiogenic cascade, i.e. migration and proliferation of endothelial cells and their two- or three-dimensional organisation into capillary-like structures (Meyer et al., 1997; Peters et al., 2002; Connolly et al., 2002).

In the following, different in vitro models for investigation and quantitation of angiogenesis are described and assessed critically (Tab. 3).

\subsection{Quantitation of endothelial cell migration}

\subsubsection{Boyden chamber}

The Boyden chamber consists of two super-imposed chambers separated by a nuclear pore polycarbonate filter with a pore size of 5-12 $\mu \mathrm{m}$ (Boyden, 1962). Basically, endothelial cells are seeded on a polycarbonate filter of the upper chamber and migration through the filter into the lower chamber is investigated (Iwahana et al., 1996; Murohara et al., 1999; Harvey et al., 2002; Staton et al., 2004; Jabbour et al., 2009). For this method the lower chamber was loaded with medium containing the proangiogenic factors to be tested. Endothelial cells were seeded into the upper chamber on the surface of a gelatine-coated polycarbonate filter in basic medium. After incubation for several hours, cells remaining on the surface of the polycarbonate filter were carefully removed and filters were fixed with methanol. Cells that migrated to the reverse side of the filter were stained

Tab. 3: Advantages and disadvantages of models for quantitation of angiogenesis and antiangiogenesis in vitro

\begin{tabular}{|c|c|c|c|}
\hline Model & Advantages & Disadvantages & References \\
\hline Migration models & $\begin{array}{l}\text { - rapid and inexpensive } \\
\text { - appropriate for cells from all } \\
\text { species including human }\end{array}$ & $\begin{array}{l}\text { - only one phase of angiogenesis } \\
\text { is considered } \\
\text { - restricted reproducibility } \\
\text { - possible false results due to } \\
\text { unspecific migration (scratch wound } \\
\text { assay) } \\
\text { - time consuming preparation (RIMAC) }\end{array}$ & $\begin{array}{l}\text { Jain et al., } 1997 \\
\text { Kruger et al., } 2001 \\
\text { Auerbach et al., } 2003\end{array}$ \\
\hline Proliferation models & $\begin{array}{l}\text { - rapid and inexpensive } \\
\text { - appropriate for cells from all } \\
\text { species including human }\end{array}$ & $\begin{array}{l}\text { - only one phase of angiogenesis } \\
\text { is considered } \\
\text { - possible false results due to initial } \\
\text { and spontaneous proliferation }\end{array}$ & $\begin{array}{l}\text { Jain et al., } 1997 \\
\text { Auerbach et al., } 2003\end{array}$ \\
\hline Tube formation models & $\begin{array}{l}\text { - appropriate for cells from all } \\
\text { species including human } \\
\text { - lumenisation of capillary-like } \\
\text { structures can be recorded }\end{array}$ & $\begin{array}{l}\text { - only one phase of angiogenesis } \\
\text { is considered } \\
\text { - possible false results due to } \\
\text { angiogenic potential of matrices } \\
\text { used for coating }\end{array}$ & $\begin{array}{l}\text { Jain et al., } 1997 \\
\text { Vailhé et al., } 2001 \\
\text { Montanez et al., } 2002 \\
\text { Auerbach et al., } 2003\end{array}$ \\
\hline All-in-one model & $\begin{array}{l}\text { - all phases of angiogenesis } \\
\text { are considered } \\
\text { - appropriate for cells from all } \\
\text { species including human } \\
\text { - inexpensive } \\
\text { - high reproducibility } \\
\text { - simple procedure } \\
\text { - only standard equipment } \\
\text { needed } \\
\text { - lumenisation of capillary-like } \\
\text { structures can be recorded }\end{array}$ & $\begin{array}{l}\text { - time-consuming } \\
\text { - large amount of pictures to } \\
\text { analyse } \\
\text { - subjective evaluation of images } \\
\text { requiring profound training of } \\
\text { investigators }\end{array}$ & $\begin{array}{l}\text { Bahramsoltani and } \\
\text { Plendl, } 2004 \\
\text { Bahramsoltani et al., } 2006 \\
\text { Bahramsoltani and } \\
\text { Plendl, } 2007\end{array}$ \\
\hline
\end{tabular}


and investigated microscopically, and defined ROI were photographed. For quantitation of angiogenesis, stained cell nuclei were quantified in the photographs by image analysis.

This method can also be used to investigate inhibitory effects of different substances on endothelial cell migration. The investigated antiangiogenic substances may be applied by coating the filter (Kuzuya et al., 1998) or by adding them to the upper or lower chamber (Minischetti et al., 2000; Ergün et al., 2001; Célérier et al., 2002; Hata et al., 2008).

\subsubsection{Scratch Wound Assay}

The "scratch wound assay" represents a simple method to quantify the migration of endothelial cells. For this purpose endothelial cells are mechanically removed from an area of a confluent cell monolayer. Subsequently, migration of cells from the remaining monolayer into this area is observed (Murohara et al., 1999; Weis et al., 2002; Wang et al., 2009). For this investigation, endothelial cells are seeded and incubated until confluence. After this, cells are scratched off with a scalpel in a certain area of the well. Subsequently, the border of the "wounded" monolayer is microscopically examined and photographed. Angiogenesis is quantified by calculating the number of endothelial cells migrated from the monolayer indicated as cells $/ \mathrm{cm}^{2}$ (Murohara et al., 1999).

\subsubsection{Radial Invasion of Matrix by Aggregated Cells (RIMAC)}

Vernon and Sage (1999) used a method to quantify migration of endothelial cells designated as "radial invasion of matrix by aggregated cells" (RIMAC).

Endothelial cells from bovine aorta were suspended in basic medium and cell concentration was estimated in suspension. A drop of this suspension was administered to a plastic platelet, which was subsequently placed upside down on a bar ("hanging drop"). After 4 days an endothelial cell aggregate developed in the drop and the platelet was turned around again. Subsequently, drop fluid was carefully extracted and the cell aggregate remained on the plastic platelet. Then a nylon ring was placed on the platelet so that the cell aggregate lay in the ring centre. The cell aggregate was doused with collagen type I solution and hardened at $37^{\circ} \mathrm{C}$ for $90 \mathrm{~min}$. Subsequently, the ring with gel was turned around, the plastic platelet was removed and the ring was doused again with collagen type I solution and hardened for $90 \mathrm{~min}$. The produced gel platelets were placed in culture wells and incubated with medium containing the growth factors to be tested over time. For quantitation of endothelial cell migration the gel platelets were removed from the plate and were put on microscopic slides in the middle of concentric rings with a distance of $10 \mu \mathrm{m}$. With the aid of these rings the distance between migrated cells and aggregate could be microscopically estimated and the mean was given as measurement for migration.

\subsection{Quantitation of endothelial cell proliferation}

Investigation of endothelial cell proliferation is one of the most frequently used methods to quantify angiogenesis in vitro (Auerbach, 2002).

\subsubsection{Colorimetric assays}

This method, developed by Kueng et al. (1989) to quantify proliferation of different cells, was adapted to endothelial cells by several investigators and is the most frequently used proliferation assay (e.g. Yoon et al., 1999; Lang et al., 2000; Minischetti et al., 2000; Yokoyama et al., 2000; Weis et al., 2002; Staton et al., 2004; Shrader et al., 2009).

The principle of this method is based on the measurement of mitochondrial activity. After incubation of endothelial cells in the growth factors to be tested, tetrazolium salt was added to medium to quantify proliferation. Catalyzed by the mitochondrial enzyme succinate dehydrogenase, tetrazolium salt is reduced by succinate to violet coloured formazan. As the number of mitochondria in a sample increases with cell number, elevated formazan development is the consequence of intensified cell proliferation. The optical density of formazan stain, which is proportional to cell amount, is measured with a spectrophotometer.

Another colorimetric method was adapted by Shichiri and Hirata (2001) and Huang et al. (2002) and is based on the fluorescence measurement of propidium-iodide incorporated into endothelial cells to quantify their proliferation.

\subsection{2 $\left({ }^{3} \mathrm{H}\right)$ Thymidine or bromo-deoxy-uridine (BrdU) incorporation}

$\left({ }^{3} \mathrm{H}\right)$ Thymidine or bromo-deoxy-uridine (BrdU) integration into cell DNA depends on DNA synthesis activity. Thus, it is frequently used to quantify endothelial cell proliferation (Murohara et al., 1999; Célérier et al., 2002; Minici et al., 2007; Hata et al., 2008). Endothelial cells cultured with test substances are incubated with $\left({ }^{3} \mathrm{H}\right)$ thymidine or BrdU. Quantitation of angiogenesis is carried out by measurement of incorporated radioactivity or fluorescence by DNA.

\subsubsection{Coulter Counter}

This is a simple method to quantify endothelial cell proliferation by counting cells with an electronic particle counter or coulter counter. For this purpose endothelial cells are incubated with pro- or antiangiogenic factors for a certain time and suspended for automatic calculation (e.g. Schor et al., 1983; Sankar et al., 1996; Vasse et al., 1999).

\subsection{Quantitation of tube formation by endothelial cells in vitro}

Spontaneous two- or three-dimensional organisation of in vitro cultured microvascular endothelial cells into string-like structures was observed for the first time in 1980 by Folkman and Haudenschild. The presence of a lumen was proven by phase contrast and transmission electron microscopy. These in vitro-developed endothelial strings were therefore defined as "capillarylike structures"; however, in the contemporary literature, they are more often named "tube-like structures". Since then, studies concerning the investigation and quantitation of capillary-like structures have been published increasingly (e.g. Montesano et al., 1983; Hoying and Williams, 1996; Nehls and Drenckhahn, 1995; Meyer et al., 1997; Peters et al., 2002). However, authors 
often used the term "capillary-like structures" independently of the existence of a lumen within the investigated structures. The presence of a lumen within such endothelial structures was only proven in very few investigations (e.g. Montesano et al., 1983; Meyer et al.; 1997).

The models for quantitation of the "capillary-like structures" can be divided into two categories: two-dimensional and threedimensional models (Vailhé et al., 2001).

\subsubsection{Two-dimensional models of in vitro angiogenesis}

In these models endothelial cells are grown in culture plates mostly coated with adhesive proteins. Alternatively, cells are seeded on surfaces of collagen, fibrin gels or Matrigel ${ }^{\circledR}$, or are covered by them. Vailhé et al. (2001) further divided the twodimensional models into short-term (up to 3 days) and longterm (more than 3 days) models of capillary-like structure development.

Peters et al. (2002) fluorescently labelled cultivated endothelial cells and quantified the developing capillary-like structures on the basis of fluorescence intensity. In this method the monolayer shows the highest fluorescent intensity, which decreases with development of the capillary-like structures when the monolayer becomes patchy. Quantitation of capillary-like structure development can also be performed by microscopy and computer-assisted evaluation of photographed wells (Connolly et al., 2002; Harvey et al., 2002).

\subsubsection{Three-dimensional models of in vitro angiogenesis}

All so far described three-dimensional models are based on the capacity of activated endothelial cells to migrate into a threedimensional matrix, consisting either of collagen- or fibrin gels, or of Matrigel ${ }^{\circledR}$. Culture medium can be added to the gel before or after its polymerisation (Vailhé et al., 2001).

Nehls and Drenckhahn (1995) developed an elegant method based on microcarriers to quantify three-dimensional migration of endothelial cells and formation of capillary-like structures. For this method plastic microcarriers were coated with gelatine and suspended with endothelial cells. After incubation for 2-4 days, the microcarriers are overgrown with endothelial cells and are then embedded in a fibrin matrix. On the following days, the number of capillary-like structures formed by migrated endothelial cells can be quantified by microscopic monitoring.

Other authors quantified the development of capillary-like structures in a fibrin matrix without carriers (Hoying and Williams, 1996; Collen et al., 1998). This so-called "tube formation assay" is currently the most frequently used model for quantitation of three-dimensional angiogenesis in vitro (e.g. Mountain et al., 2008; Liu et al., 2008; Saiki et al., 2008; Limaye et al., 2009).

A method to quantify an existing lumen within capillary-like structures, formed in a three-dimensional matrix, was only described by Meyer et al. (1997). Endothelial cells are seeded on a collagen type I gel, cultivated in the presence of growth factors and finally fixed with paraformaldehyde and glutaraldehyde.
Fixed gel cones are removed from wells and divided into three pieces by two cuts vertical to the surface and the middle block is used further. The block is divided into pieces of the same size by cuts parallel to the surface. Serial sections of each piece are then stained and microscopically investigated. For quantitation of angiogenesis the number of consecutive serial sections crossed by a tubular structure with a lumen is determined. By means of known thickness of sections, the length of the capillary-like structures can be calculated.

An innovative method to quantify three-dimensional vessel growth was established by Lange et al. (2009). Three-dimensional spherical cell aggregates, so-called embryoid bodies, are generated from embryonic stem cells within a spinner flask and are incubated with several growth factors. For quantitation of, in this case, vasculogenesis, CD31-stained cells are examined by confocal laser scanning, and full-frame images are taken in zdirection, giving a three-dimensional projection of the vascular structures within the embryoid bodies. Quantitation is carried out by counting the branching points of vascular structures in relation to the size of the respective embryoid body.

\subsection{All-in-one model of in vitro angiogenesis}

As already mentioned, different methods of angiogenesis quantitation exist, but none of them allows quantitation of all steps of the angiogenic cascade in one assay. For this reason authors of this review developed an all-in-one method of in vitro angiogenesis (Bahramsoltani and Plendl, 2004; Bahramsoltani et al., 2006).

Endothelial cells are seeded on gelatine-coated wells and cultivated in growth media for 60 days. During incubation, differences in cellular morphology, i.e. sprouting, linear side-by-side arrangement and three-dimensional organisation into capillarylike structures (Fig. 4), can be observed in a time-dependent manner by phase contrast microscopy. These phases of in vitro angiogenesis have been divided into strictly defined stages.

On the first day of investigation, visual fields are randomised and defined per coordinates. Extensive validation of this method showed that representative quantitation can be carried out in 4

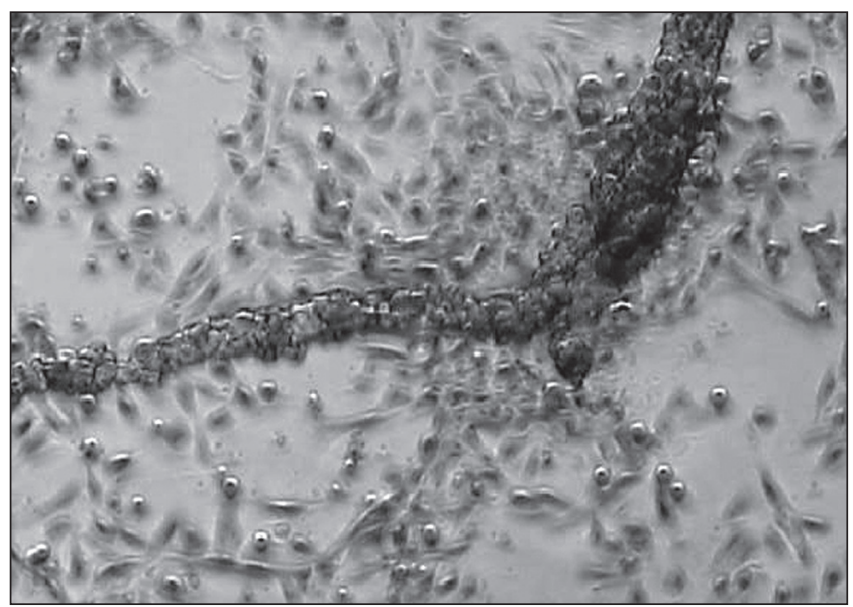

Fig. 4: Quantitation of angiogenesis in vitro: All-in-one model Capillary-like structure, phase contrast microscopy, 100x 
wells and 4 visual fields per well. The cellular changes in these visual fields are documented in equal intervals. The obtained cell images are assigned to the respective stage of angiogenesis, and a time-dependent course of angiogenesis is drawn.

This method can also be used for quantitation of antiangiogenesis (Bahramsoltani and Plendl, 2007). Moreover, using this approach, different pathways of antiangiogenesis can be followed. As example, it was shown that angiostatin-induced antiangiogenesis resulted in an inverse angiogenesis. Conversely, addition of suramine initially resulted in increased angiogenesis, but long-term incubation ultimately led to disintegration of endothelial structures, thus establishing the antiangiogenic effects of suramine.

\section{Critical assessment of angiogenesis models}

In this review many existing models of angiogenesis are presented with their advantages and disadvantages summarised in tables 1-3. Clearly, the main disadvantage of in vivo models is the requirement of extremely high number of animals for experiments, which go through long lasting stress and pain. Moreover, the requirement of sophisticated and expensive equipment and high skills of researchers to perform the surgery allows performing of such experiments only in a limited number of labs. Conversely, in vitro angiogenesis methods can be easily performed in a basically equipped lab in a relatively short time. Certainly, the cells must first be isolated from animal or human tissues, but one cell preparation is enough for many in vitro experiments. A further disadvantage of in vivo models of angiogenesis is the fact that only the final product of angiogenesis, i.e. vessels, can be quantified, whereas in vitro models focus on the process itself, i.e. angiogenesis. An optimal solution could be the use of ex vivo models, which combine the in vivo situation with in vitro possibilities. However, the reproducibility of such models is extremely low, making it practically impossible to use them for screening studies and quantitation of angiogenesis. Nevertheless, in vivo studies remain the only possibility to follow the toxicity, immune reactions, biotransformation of tested substances, etc., but they are less suitable for biochemical cellular and molecular investigations. For these purposes, in vitro methods are indispensable. However, when choosing the in vitro method, it must be considered whether investigation of the number of developing vessels is of importance or of the way they develop. Another problem is the choice of endothelial cells, owing to their high heterogeneity. Moreover, almost all in vitro methods allow only one-sided insight into the very complex process of angiogenesis, because quantitation of angiogenesis is carried out based on migration and proliferation of endothelial cells only. Therefore, a combination of more than one assay may be necessary in order to determine the pro- or antiangiogenic effect of a substance on endothelial cells. To date only one in vitro model covers all angiogenic phases. In this model, new potential pro- or antiangiogenic drugs can be investigated easily and relatively fast. An integral point of in vitro models are the cells used. Many researchers use immortalised cell lines due to the high reproducibility of results. But the value and significance of studies with artificially modified cells remains questionable as the comparability to the in vivo situation is questionable.

It is desirable that in future in vitro methods dominate preliminary screening studies, whereas in vivo trials should be limited to the last grids in the chain of angiogenesis or antiangiogenesis investigations.

\section{Angiogenesis research in the future}

The future of angiogenesis research will certainly focus on the further development of better quantitation, more rapid assays relevant to clinical research, higher reproducibility and ease of execution, well known goals defined by Jain et al. (1997). Further development of computer-assisted micro-imaging methods, such as MRI and CT, will probably allow improvement and/or development of new in vivo models with reduced invasiveness, less stress and reduced mortality rate of animals. Moreover, further replacement of in vivo methods can only be reached by improved lab internal and external validation of existing and new in vitro methods to obtain the qualification for validation on an international regulatory level.

\section{References}

Abshagen, K., Schrodi, I., Gerber, T. and Vollmar, B. (2008). In vivo analysis of biocompatibility and vascularization of the synthetic bone grafting substitute NanoBone(R). J. Biomed. Mater. Res. A., E-pub ahead of print.

Akimoto, T., Liapis, H. and Hammerman, M. R. (2002). Microvessel formation from mouse embryonic aortic explants is oxygen and VEGF dependent. Am. J. Physiol. Regulatory Integrative Comp. Physiol. 283, R487-R495.

Algire, G. H. (1943). An adaption of the transparent-chamber technique to the mouse. J. Natl. Cancer Inst. USA 4, 1-11.

Auerbach, R. (2002). Angiogenesis assays. Trends Mol. Med. 8, 243.

Auerbach, R., Akhtar, N., Lewis, R. L. and Shinners, B. L. (2000). Angiogenesis assays: Problems and pitfalls. Cancer Metastasis Rev. 19, 167-172.

Auerbach, R., Auerbach, W. and Polakowski, I. (1991). Assays for angiogenesis: a review. Pharmacol. Ther. 51, 1-11.

Auerbach, R., Kubai, L., Knighton, D. and Folkman, J. (1974). A simple procedure for the long-term cultivation of chicken embryos. Dev. Biol. 41, 391-394.

Auerbach, R., Lewis, R., Shinners, B. et al. (2003). Angiogenesis assays: a critical overview. Clin. Chem. 49, 32-40.

Auerbach, W. and Auerbach, R. (1994). Angiogenesis inhibition: a review. Pharmacol. Ther. 63, 265-311.

Ausprunk, D. H., Knighton, D. R. and Folkman, J. (1975). Vascularization of normal and neoplastic tissues grafted to the chick chorioallantois. Role of host and preexisting graft blood vessels. Am. J. Pathol. 79, 597-628.

Babaei, S. and Stewart, D. J. (2002). Overexpression of endothelial NO synthase induces angiogenesis in a co-culture model. Cardiovasc. Res. 55, 190-200.

Bahramsoltani, M., Käßmeyer, S. and Plendl, J. (2006). A 
novel quantitative in vitro model of angiogenesis. ALTEX 23 Suppl., 265-269.

Bahramsoltani, M. and Plendl, J. (2004). A new in vitro model to quantify angiogenesis. ALTEX 21, 227-244.

Bahramsoltani, M. and Plendl, J. (2007). Different ways to antiangiogenesis by angiostatin and suramin, and quantitation of angiostatin-induced antiangiogenesis. APMIS 115, 30-46.

Basaki, Y., Chikahisa, L., Aoyagi, K. et al. (2001). $\gamma$-Hydroxybutyric acid and 5-fluorouracil, metabolites of UFT, inhibit the angiogenesis induced by Vascular Endothelial Growth Factor. Angiogenesis 4, 163-173.

Bell, E. J. and Brickell, P. M. (1997). Replication-competent retroviral vectors for expressing genes in avian cells in vitro and in vivo. Mol. Biotechnol. 7, 289-298.

Blacher, S., Devy, L., Burbridge, M. F. et al. (2001). Improved quantification of angiogenesis in the rat aortic ring assay. Angiogenesis 4, 133-142.

Blackwell, K. L., Haroon, Z. A., Shan, S. et al. (2000). Tamoxifen inhibits angiogenesis in estrogen receptor-negative animal models. Clin. Cancer Res. 6, 4359-4364.

Boyden, S. (1962). The chemotactic effect of mixture of antibody antigen on polymorphonuclear leukocytes. J. Exp. Med. 115, 453-466.

Brown, K. J., Maynes, S. F., Bezos, A. et al. (1996). A novel in vitro assay for human angiogenesis. Lab. Invest. 75, 539555 .

Brooks, P. C., Montgomery, A. M. and Cheresh, D. A. (1999). Use of 10-day-old chick embryo model for studying angiogenesis. Meth. Mol. Biol. 129, 257-269.

Bruns, C. J., Liu, W., Davis, D. W. et al. (2000). Vascular endothelial growth factor is an in vivo survival factor for tumor endothelium in a murine model of colorectal carcinoma liver metastases. Cancer 89, 488-499.

Cao, R., Brankenhielm, E., Li, X. et al. (2002). Angiogenesis stimulated by PDGF-CC, a novel member in the PDGF family, involves activation of PDGFR-alphaalpha and alphabeta receptors. FASEB 16, 1575-1583.

Célérier, J., Cruz, A., Lammandé, N. et al. (2002). Angiotensinogen and its cleavage derivatives inhibit angiogenesis. Hypertension 39, 224-235.

Collen, A., Koolwijk, P., Kroon, M. and van Hinsbergh, W. M. (1998). Influence of fibrin structure on the formation and maintenance of capillary-like tubules by human microvascular endothelial cells. Angiogenesis 2, 153-165.

Connolly, J. O., Simpson, N., Hewlett, L. and Hall, A. (2002). Rac regulates endothelial morphogenesis and capillary assembly. Mol. Biol. Cell 13, 2474-2485.

Cross, L. M., Cook, M. A., Lin, S. et al. (2003). Rapid analysis of angiogenesis drugs in a live fluorescent zebrafish assay. Arterioscler. Thromb. Vasc. Biol. 23, 911-912.

Denis, F., Bougnoux, P., de Poncheville, L. et al. (2002). In vivo quantitation of tumour vascularisation assessed by Doppler sonography in rat mammary tumours. Ultrasound. Med. Biol. 28, 431-437.

Dong, Z., Neiva, K. G., Jin, T. et al. (2007). Quantification of human angiogenesis in immunodeficient mice using a photon counting-based method. Biotechniques 43, 73-77.

Doukas, C. N., Maglogiannis, I., Chatziioannou, A. and Papapetropoulos, A. (2006). Automated angiogenesis quantification through advanced image processing techniques. Conf. Proc. IEEE Eng. Med. Biol. Soc. 1, 2345-2348.

Endrich, B., Asaishi, K., Goetz, A. and Messmer, K. (1980). Technical report - a new chamber technique for microvascular studies in unanaesthetized hamsters. Res. Exp. Med. 177, 125-134.

Ergün, S., Kilic, N., Wurmbach, J.-H. et al. (2001). Endostatin inhibits angiogenesis by stabilization of newly formed endothelial tubes. Angiogenesis 4, 193-206.

Eriksson, J. and Löfberg, J. (2000). Development of the hypochord and dorsal aorta in the zebrafish embryo (Danio rerio). J. Morph. 244, 167-176.

Feldner, J., Becker, T., Goishi, K. et al. (2005). Neuropilin-1a is involved in trunk motor axon outgrowth in embryonic zebrafish. Dev. Dyn. 234, 535-549.

Gaudric, A., N'guyen, T., Moenner, M. et al. (1992). Quantification of angiogenesis due to basic fibroblast growth factor in a modified rabbit corneal model. Ophthalmic. Res. 24, 181-188.

Gimbrone, M. A. Jr., Cotran, R. S., Leapman, S. B. and Folkman, J. (1974). Tumor growth and neovascularisation: an experimental model using the rabbit cornea. J. Natl. Cancer Inst. USA 52, 413-419.

Guo, L., Burke, P., Lo, S.-H. et al. (2001). Quantitative analysis using confocal laser scanning microscopy. Angiogenesis 4, 187-191.

Hata, Y., Miura, M., Nakao, S. et al. (2008). Antiangiogenic properties of fasudil, a potent Rho-kinase inhibitor. Jpn. J. Ophthalmol 52, 16-23.

Henkind, P. (1978). Ocular neovascularisation. Am. J. Ophthal. 85, 287-301.

Harvey, K., Welch, Z., Kovola, T. et al. (2002). Comparative analysis of in vitro angiogenic activities of endothelial cells of heterogeneous origin. Microvasc. Res. 63, 316-326.

Hoffmann, J., Schirner, M., Menrad, A. and Schneider, M. R. (1997). A highly sensitive model for quantification of in vivo tumor angiogenesis induced by alginate-encapsulated tumor cells. Cancer Res. 57, 3847-3851.

Hoying, J. B. and Williams, S. K. (1996). Measurement of endothelial cell migration using an improved linear migration assay. Microcirculation 3, 167-174.

Huang, S.-M., Li, J., Armstrong, E. A. and Harari, P. M. (2002). Modulation of radiation response and tumor-induced angiogenesis after epidermal growth factor receptor inhibition by ZD 1839 (Iressa). Cancer Res. 62, 4300-4306.

Iwahana, M., Nakayama, Y., Tanaka, N.G. et al. (1996). Quantification of tumour-induced angiogenesis by image analysis. Int. J. Exp. Path. 77, 109-114.

Jabbour, M. N., Elder, J. B., Samuelson, C. G. et al. (2009). Aberrant angiogenic characteristics of human brain arteriovenous malformation endothelial cells. Neurosurgery 64, 139146 .

Jain, R. K., Schlenger, K., Höckel, M. and Ynan, F. (1997). 
Quantitative angiogenesis assays: Progress and problems. Nature Med.3, 1203-1208.

Joussen, A. M., Germann, T. and Kirchhof, B. (1999). Effect of thalidomide and structurally related compounds on corneal angiogenesis is comparable to their teratological potency. Graefe's Arch. Clin. Exp. Ophthalmol. 237, 952-961.

Jung, M. H., Lee, S. H., Ahn, E. M. and Lee, Y. M. (2009). Decursin and decursinol angelate inhibit VEGF-induced angiogenesis via suppression of the VEGFR2 signaling pathway. Carcinogenesis, E-pub ahead of print.

Jung, S. P., Siegrist, B., Wade, M. R. et al. (2001). Inhibition of human angiogenesis with heparin and hydrocortisone. Angiogenesis 4, 175-186.

Kazanskaya, O., Ohkawara, B., Heroult, M. et al. (2008). The Wnt signaling regulator R-spondin 3 promotes angioblast and vascular development. Development 135, 3655-3664.

Kiessling, F., Huppert, J. and Palmowski, M. (2009). Functional and molecular ultrasound imaging: concepts and contrast agents. Curr. Med. Chem. 16, 627-642.

Knighton, D. R., Fiegel, V. D. and Phillips, G. D. (1991). The assays for angiogenesis. Progr. Clin. Biol. Res. 365, 291299.

Kruger, E. A., Duray, P. H., Price, D. K. et al. (2001). Approaches to preclinical screening of antiangiogenic agents. Sem. Oncology 28, 570-576.

Kruger, E. A. and Figg, W. D. (2001). Protein binding alters the activity of Suramin, Carboxyamidotriazole, and UCN-01 in an ex vivo rat aortic ring angiogenesis assay. Clin. Cancer Res. 7, 1867-1872.

Kueng, W., Silber, E. and Eppenberger, U. (1989). Quantification of cells cultured on 96-well plates. Anal. Biochem. 182, 16-19.

Kuzuya, M., Satake, S., Ai, S. et al. (1998). Inhibition of angiogenesis on glycated collagen lattices. Diabetologia 41 , 491-499.

Lang, I., Hoffmann, C., Olip, H. et al. (2000). Differential mitogenic responses of human macrovascular and microvascular endothelial cells to cytokines underline their phenotypic heterogeneity. Cell Prolif. 34, 143-155.

Lange, S., Heger, J., Euler, G. et al. (2009). Platelet-derived growth factor $\mathrm{BB}$ stimulates vasculogenesis of embryonic stem cell-derived endothelial cells by calcium-mediated generation of reactive oxygen species. Cardiovasc. Res. 81 , 159-168.

Langer, R. and Folkman, J. (1976). Polymers for the sustained release of proteins and other macromolecules. Nature 263, 797-799.

Lawson, N. D. and Weinstein, B. M. (2002). In vivo imaging of embryonic vascular development using transgenic zebrafish. Dev. Biol. 248, 307-318.

Lee, P., Goishi, K., Davidson, A. J. et al. (2002). Neuropilin-1 is required for vascular development and is a mediator of VEGF-dependent angiogenesis in zebrafish. Proc. Natl. Acad. Sci. USA 99, 10470-10475.

Lehr, H. A., Leunig, M., Menger, M. D. et al. (1993). Dorsal skinfold chamber technique for intravital microscopy in nude mice. Am. J. Pathol. 143, 1055-1062.

Lenander, C. and Holmgren, L. (1999). A novel method of visualizing vessels in human tumor biopsies. Angiogenesis 3, 291-293.

Liapakis, I. D., Anagnostoulis, S., Karayiannakis, A. J. et al. (2008). Recombinant leptin administration improves early in full-thickness skin flaps: an experimental study. In Vivo 22, 247-252.

Lichtenberg, J., Hansen, C. A., Skak-Nielsen, T. et al. (1997). The rat subcutaneus air sac model: a new and simple method for in vivo screening of antiangiogenesis. Pharmacol. Toxicol. 81, 280-284.

Lichtenberg, J., Hjarnaa P.-J., Kristjansen, P. E. et al. (1999). The rat subcutaneus air sac model: a quantitative assay of antiangiogenesis in induced vessels. Pharmacol. Toxicol. 84, 34-40.

Limaye, V., Xia, P., Hahn, C. et al. (2009). Chronic increases in sphingosine kinase-1 activity induce a pro-inflammatory, pro-angiogenic phenotype in endothelial cells. Cell Mol. Biol. Lett., E-pub ahead of print.

Lindner, R. J. (2004). Molecular imaging with contrast ultrasound and targeted microbubbles. J. Nucl. Cardiol. 11, 215221.

Liu, Y., Sainz, I. M., Pixley, R. et al. (2008). The inhibition of tube formation in a collagen-fibrinogen, three-dimensional gel by cleaved kininogen (HKa) and HK domain 5 (D5) is dependent on Src family kinases. Exp. Cell Res. 314, 774788.

Lucidarme, O., Kono, Y., Corbeil, J. et al. (2006). Angiogenesis: noninvasive quantitative assessment with contrast-enhanced functional US in murine model. Radiology 239, 730-739.

Ma, A. Ch., Lin, R., Chan, P.-K. et al. (2007). The role of survivin in angiogenesis during zebrafish embryonic development. BMC Dev. Biol. 7, 50.

McDonald, D. M. and Choyke, P. L. (2003). Imaging of angiogenesis: from microscope to clinic. Nat. Med. 9, 713-725.

Menger, M. D., Laschke, M. W. and Vollmar, B. (2002). Viewing the microcirculation through the window: some twenty years experience with the hamster dorsal skinfold chamber. Eur. Surg. Res. 34, 83-91.

Meyer, G. T., Matthias, L. J., Noack, L. et al. (1997). Lumen formation during angiogenesis in vitro involves phagocytic activity, formation and secretion of vacuoles, cell death, and capillary tube remodelling by different populations of endothelial cells. Anat. Rec. 249, 327-340.

Minici, F., Miceli, F., Tiberi, F. et al. (2007). Ghrelin in vitro modulates vasoactive factors in human umbilical vein endothelial cells. Fertil. Steril. 88, 1158-1166.

Minischetti, M., Vacca, A., Ribatti, D. et al. (2000). TNP-470 and recombinant human interferon- $\alpha 2 \mathrm{a}$ inhibit angiogenesis synergistically. Brit. J. Haemat. 109, 829-837.

Montanez, E., Casaroli-Marano, R. P., Vilaro, S. and Pagan, R. (2002). Comparative study of tube assembly in three-dimensional collagen matrix and on Matrigel coats. Angiogenesis 5, 167-172.

Montesano, R., Vassalli, J. D., Baird, A. et al. (1986). Basic 
fibroblast growth factor induces angiogenesis in vitro. Proc. Natl. Acad. Sci. USA 83, 7297-7301.

Mountain, D. J., Singh, M. and Singh, K. (2008). Interleukinlbeta-mediated inhibition of the process of angiogenesis in cardiac microvascular endothelial cells. Life Sci., E-pub ahead of print.

Murohara, T., Witzenbichler, B., Spridopoulos, I. et al. (1999). Role of endothelial nitric oxide synthase in endothelial cell migration. Arterioscler. Thromb. Vasc. Biol. 19, 1156-1161.

Nehls, V. and Drenckhahn, D. (1995). A novel, microcarrierbased in vitro assay for rapid and reliable quantification of three-dimensional cell migration and angiogenesis. Microvasc. Res. 50, 311-322.

Nguyen, M., Shing, Y. and Folkman, J. (1994). Quantitation of angiogenesis and antiangiogenesis in the chick chorioallantoic membrane. Microvasc. Res. 47, 31-40.

Nicosia, R. F. and Ottinetti, A. (1990a). Growth of microvessels in serum-free matrix culture of rat aorta: a quantitative assay of angiogenesis in vitro. Lab. Invest. 63, 115-122.

Nicosia, R. F. and Ottinetti, A. (1990b). Modulation of microvascular growth and morphogenesis by reconstituted basement membrane gel in three-dimensional cultures of rat aorta: a comparative study of angiogenesis in matrigel, collagen, fibrin, and plasma clot. In Vitro Cell Dev. Biol. 26, 119-128.

Ny, A., Autiero, M. and Carmeliet, P. (2006). Zebrafish and Xenopus tadpoles: Small animal models to study angiogenesis and lymphangiogenesis. Exp. Cell Res. 312, 684-693.

Ober, E. A., Olofsson, B., Mäkinen, T. et al. (2004). Vegfc is required for vascular development and endoderm morphogenesis in zebrafish. EMBO Rep. 5, 78-84.

Oikawa, T., Sasaki, M., Inose, M. et al. (1997). Effects of cytogenin, a novel microbial product, on embryonic and tumor cell-induced angiogenic responses in vivo. Anticancer Res. 17, 1881-1886.

Papenfuss, H. D., Gross, J. F., Intaglietta, M. and Treese, F. A. (1979). A transparent access chamber for the rat dorsal skin fold. Microvasc. Res. 18, 311-318.

Peters, K., Schmidt, H., Unger, R. E. et al. (2002). Softwaresupported image quantification of angiogenesis in an in vitro culture system: application to studies of biocompatibility. Biomaterials 23, 3413-3419.

Plunkett, M. L. and Hailey, J. A. (1990). An in vivo quantitative angiogenesis model using tumor cells entrapped in alginate. Lab. Invest. 62, 510-517.

Ramsauer, M., Krause, D. and Dermietzel, R. (2002). Angiogenesis of the blood-brain barrier in vitro and the function of cerebral pericytes. FASEB 16, 1274-1276.

Ribatti, D., Crivellato, E., Candussio, L. et al. (2002). Angiogenic activity of rat mast cells in the chick embryo chorioallantoic membrane is down-regulated by treatment with recombinant human $\alpha-2 \mathrm{a}$ interferon and partly mediated by fibroblast growth factor-2. Haematologica 87, 465-471.

Ribatti, D., Gualandris, A., Bastaki, M. et al. (1997). New model for the study of angiogenesis and antiangiogenesis in the chick chorioallantoic membrane: the gelatin sponge / chorioallantoic membrane assay. J. Vasc. Res. 34, 455-463.
Ribatti, D., Nico, B., Vacca, A. et al. (2001). Chorioallantoic membrane capillary bed: a useful target for studying angiogenesis and anti-angiogenesis in vivo. Anat. Rec. 264, 317324.

Ribatti, D., Vacca, A., Roucali, L. and Damacco, F. (1996). The chick embryo chorioallantoic membrane as a model for in vivo research on angiogenesis. Int. J. Dev. Biol. 40, 11891197.

Rubinstein, A. L. (2003). Zebrafish: from disease modeling to drug discovery. Curr. Opin. Discov. Devel. 6, 218-223.

Runkel, S., Hunter, N. and Milas, L. (1991). An intradermal assay for quantification and kinetic studies of tumor angiogenesis in mice. Radiation Res. 126, 237-243.

Saiki, A., Watanabe, F., Murano, T. et al. (2006). Hepatocyte growth factor secreted by cultured adipocytes promotes tube formation of vascular endothelial cells in vitro. Int. J. Obes. (Lond) 30, 1676-1684.

Sankar, S., Mahooti-Brooks, N., Bensen, L. et al. (1996). Modulation of transforming growth factor $\beta$ receptor levels on microvascular endothelial cells during in vitro angiogenesis. J. Clin. Invest. 97, 1436-1446.

Schor, A. M., Schor, S. L. and Allen, T. D. (1983). Effects of culture conditions on the proliferation, morphology and migration of bovine aortic endothelial cells. J. Cell Sci. 62, 267285.

Schwerte, T. and Pelster, B. (2000). Digital motion analysis as a tool for analyzing the and performance of the circulatory system in transparent animals. J. Exp. Biol. 203, 1659-1669.

Semba, T., Funahashi, Y., Naoto, O. et al. (2004). An angiogenesis inhibitor E7820 shows broad-spectrum tumor growth inhibition in a xenograft model: possible value of integrin alpha2 on platelets as a biological marker. Clin. Cancer Res. 10, 1430-1438.

Serbedzija, G. N., Flynn, E. and Willet, C. E. (1999). Zebrafish angiogenesis: A new model for drug screening. Angiogenesis 3, 353-359.

Shan, S., Lockhart, A. C., Saito, W. Y. et al. (2001). The novel tubulin-binding drug BTO-956 inhibits R3230AC mammary carcinoma growth and angiogenesis in Fischer 344 rats. Clin. Cancer Res. 7, 2590-2596.

Sheu, J. R., Fu, C. C., Tsai, M. L. and Chung, W. J. (1998). Effect of U-995, a potent shark cartilage-derived angiogenesis inhibitor, on anti-angiogenesis and anti-tumor activities. Anticancer Res. 18, 4435-4441.

Shichiri, M. and Hirata, Y. (2001). Antiangiogenesis signals by endostatin. FASEB 15, 1044-1053.

Shrader, C. D., Bailey, K. M., Konat, G. W. et al. (2009). Insulin enhances proliferation and viability of human umbilical vein endothelial cells. Arch. Dermatol. Res. 301, 159-166.

Spanel-Borowski, K., Schnapper, U. and Heymer, B. (1988). The chick chorioallantoic membrane assay in the assessment of angiogenic factors. Biomed. Res. 9, 253-260.

Staton, C. A., Brown, N. J., Rodgers, G. R. et al. (2004). Alphastatin, a 24-amino acid fragment of human fibrinogen, is potent new inhibitor of activated endothelial cells in vitro and in vivo. Blood 103, 601-606. 
Tong, S., Chen, Q., Shan, S.Q. et al. (2006). Quantitative comparison of the inhibitory effects of GW5638 and tamoxifen on angiogenesis in the cornea pocket assay. Angiogenesis 9 , 53-58.

Torres Filho, I. P., Hartley-Asp, B. and Borgström, P. (1995). Quantitative angiogenesis in a syngeneic tumor spheroid model. Microvasc. Res. 49, 212-226.

Ushiyama, A., Yamada, S. and Ohkubo, C. (2004). Microcirculatory parameters measured in subcutaneous tissue of the mouse using a novel dorsal skinfold chamber. Microvasc. Res. 68, 147-152.

Vailhé, B., Vittet, D. and Feige, J.-J. (2001). In vitro models of vasculogenesis and angiogenesis. Lab. Invest. 81, 439-452.

Vajkoczy, P., Thurnher, A., Hirth, K. P. et al. (2000). Measuring VEGF-Flk-1 activity and consequences in vivo using intravital microscopy: clinical applications. The Oncologist 5 , 16-19.

Vasse, M., Pourtan, J., Trochon, V. et al. (1999). Oncostatin $\mathrm{M}$ induces angiogenesis in vitro and in vivo. Arterioscler. Thromb. Vasc. Biol. 19, 1835-1842.

Velazquez, O. C., Snyder, R., Lin, Z.-J. et al. (2002). Fibroblast-dependent differentiation of human microvascular endothelial cells into capillary-like 3-dimensional networks. FASEB 16, 1316-1318.

Vernon, R. B. and Sage, E. H. (1999). A novel, quantitative model for study of endothelial cell migration and sprout formation within three-dimensional collagen matrices. Microvasc. Res. 57, 118-133.

Vollmar, B., Laschke, M. W., Rohan, R. et al. (2001). In vivo imaging of physiological angiogenesis from immature to preovulatory ovarian follicles. Am. J. Path. 159, 1661-1670.

Wang, X. H., Chen, S. F., Jin, H. M. and Hu, R. M. (2009). Differential analyses of angiogenesis and expression of growth factors in micro- and macrovascular endothelial cells of type 2 diabetic rats. Life Sci. 84, 240-249.

Wang, T. and Shi, W. (2009). Expression of fibroblast activation proteins in corneal stromal neovascularization. Curr. Eye Res. 34, 112-117.

Weis, M., Heeschen, C., Glassford, A. J. and Cooke, J. P. (2002). Statins have biphasic effects on angiogenesis. Circulation 105, 739 .
Wild, R., Ramakrishnan, S., Sedgewick, J. and Griffioen, A. W. (2000). Quantitative assessment of angiogenesis and tumor vessel architecture by computer-assisted digital image analysis: effects of VEGF-toxin conjugate on tumor microvessel density. Microvasc. Res. 59, 368-376.

Willmann, J. K., Paulmurugan, R., Chen, K. et al. (2008). US imaging of tumor angiogenesis with microbubbles targeted to vascular endothelial growth factor receptor type 2 in mice. Radiology 246, 508-518.

Yamamoto, K., Kimura, T., Sugitachi, A. and Matsuura, N. (2009). Anti-angiogenic and anti-metastatic effects of beta1,3-D-glucan purified from Hanabiratake, Sparassis crispa. Biol. Pharm. Bull. 32, 259-263.

Yokoyama, Y., Dhanabal, M., Griffioen, A. W. et al. (2000). Synergy between angiostatin and endostatin: inhibition of ovarian cancer growth. Cancer Res. 60, 2190-2196.

Yoon, S. S., Eto, H., Lin, C. et al. (1999). Mouse endostatin inhibits the formation of lung and liver metastases. Cancer Res. 59, 6251-6256.

Zhong, T. P., Childs, S., Leu, J. P. and Fishman, M. C. (2001). Gridlock signaling pathway fashions the first embryonic artery. Nature 414, 216-220.

Ziche, M., Morbidelli, L., Masini, E. et al. (1994). Nitric oxide mediates angiogenesis in vivo and endothelial cell growth and migration in vitro promoted by substance P. J. Clin. Invest. $94,2036-2044$.

\section{Acknowledgement}

We thank Jana Müller for the drawings.

\section{Correspondence to}

Dr. Mahtab Bahramsoltani

Freie Universität Berlin

Fachbereich Veterinärmedizin

Institut für Veterinär-Anatomie

Koserstr. 20

14195 Berlin

Germany

e-Mail: bahramsoltani.mahtab@vetmed.fu-berlin.de 